\title{
Microcomputer Application for Instrumentation Development in Drip Irrigation System
}

\author{
Mohd. Hudzari Razali ${ }^{1}$, Mohd Noorman Masrek², Syazili Roslan ${ }^{1, *}$ \\ ${ }^{1}$ Faculty of Agriculture and Biotechnology, Universiti Sultan Zainal Abidin (UniSZA), Kuala Terengganu, Malaysia \\ ${ }^{2}$ Faculty of Information Management, Universiti Teknologi MARA (UiTM), Shah Alam, Selangor, Malaysia \\ *Corresponding author: leecopper_86@yahoo.com.my
}

Received December 27, 2012; Revised April 22, 2013; Accepted May 03, 2013

\begin{abstract}
Drip irrigation is the most water efficient system available to water garden. Some systems are so efficient that they only allow a few liters of water per hour to fall into the soil and the best way to water the plants at ground level where they need it the most. Installing an irrigation system such as sprinkler or drip system without automation has always been a difficult and frustrating problem for homeowners, contractors and growers alike. An ideal choice would be to use an irrigation controller, which can be the greatest help in conserving water and time. With the right controller, the right amount of water will be able to apply, at the right time, for optimum plant growth. In this study, the amounts of water that produce from microcontrollers and from different water pumps are measure. The result show the average water produced is similar. Microcomputer or controller can manage the flow of water through the irrigation system. Simple controllers such as a mechanical tap timer only need to you set the watering time required. More complex controllers are capable of watering different garden zones at different times and even on different days. It is an essential tool to apply water in the necessary quantity and at the right time to sustain agricultural production and to achieve high levels of efficiency in water, energy and chemical uses.
\end{abstract}

\section{Keywords: microcontroller, computer application, instrumentation, drip irrigation, farm mechanization}

\section{Introduction}

Agricultural irrigation is highly important in crop production everywhere in the world. Therefore, efficient water management plays an important role in the irrigated agricultural cropping systems [1,2,3]. Traditional instrumentation based on discrete and wired solutions, presents many difficulties on measuring and control systems especially over the large geographical areas. Therefore, an automation technology and its apparatus such as drip irrigation, sensors and remote control is provided for the optimal usage of water resources in agricultural areas [4]. One of the most important components of an automatic irrigation system is the irrigation controller (also called a timer or clock). Controller is one of the instruments used as an irrigation timing mechanism. The controller signals the automatic control valves when to open and close on a preset program or based on sensor readings [5]. Once programmed, the controller determines when, how often, and how long each valve is open. The right controller, properly scheduled, can result in significant water savings and lower water bills. There are two basic types of controllers, electric and hydraulic [6,7]. Most automatic irrigation valves are diaphragm valves in which the water above the diaphragm must be discharged for the valve to open. In a hydraulic system, the controller and valves are connected via small plastic tubes approximately $4 \mathrm{~mm}(1 / 4$ in $)$ in diameter. The controller opens the tube connected to the valve, allowing that valve to open. There are broadly two categories of irrigation controllers: domestic ones for gardening applications, and professional controllers for more demanding agricultural applications

It was initially developed for the agricultural industry but it is now extremely popular in Australian residential gardens, due to their water efficiency. Some advantages of drip irrigation are minimized fertilizer or nutrient loss due to localized application of water, highly efficient water distribution, allows recycled water to be used safely, maintains water within the plant's root zone where it is most needed, reduces soil erosion, does not waste water and etc. but, there are still disadvantages need to be considered such as system may cost more to install initially than other irrigation types, the sun may affect the lifespan of the tubes used in the system and the system may clog if not properly filtered and maintained $[8,9,10]$.

The type of irrigation controller that was used in UniSZA farm is domestic controller. Domestic controller can only open/close zones based on time duration, without any feedback from the irrigation process [11]. This domestic controller is usually for gardening application or smaller area. Compared to domestic controller, professional irrigation controllers can irrigate based on volume (quantities defined in cubic meters / Gallons), receive feedback from the process, and react to actual events happening during the process. For example, the typical professional controller will calculate the actual flow rate running in the system when a specific zone is operated, compare this to a pre-configured required amount, and adjust the irrigation process if deviation from 
the zone's flow rate is detected; This mechanism is called "Flow monitoring", and can prevent irrigation when a burst is occurring in the main line or in the zone's hydraulic components $[12,13]$. The controller can also alert the operator locally via its interface, or remotely by sending an SMS (Short Message System) or a message to a central control.

\section{Method}

An irrigation controller is a device to operate automatic irrigation systems such as lawn sprinklers and drip irrigation systems. Most controllers have a means of setting the frequency of irrigation, the start time, and the duration of watering. Some controllers have additional features such as multiple programs to allow different watering frequencies for different types of plants, rain delay settings, input terminals for sensors such as rain and freeze sensors, soil moisture sensors, weather data, remote operation, etc. Figure 1, Figure 2 and Figure 3 show the instrumentation used for micro irrigation system.

1. Button ON/AUTO/OFF of the controller is set to AUTO

2. Button TIMER is pressed

3. Button WEEK is pressed to adjust the day

4. Button HOUR is pressed to set the desired time to on the controller. For example 00:20 is set to on the controller

5. Button TIMER is pressed again to set time to off the controller. For example duration for the device is 5 minutes. Thus 00:25 is set to off the controller

6. Step 4 and 5 is repeated for another 10 minutes with 5 minutes duration respectively

7. The controller is plug in to the plug and the plug is switch on

8. The device is then operating based on the time set

9. Water from the drip is collected into the bottle

10 . Volume of water is measured using measuring cylinder

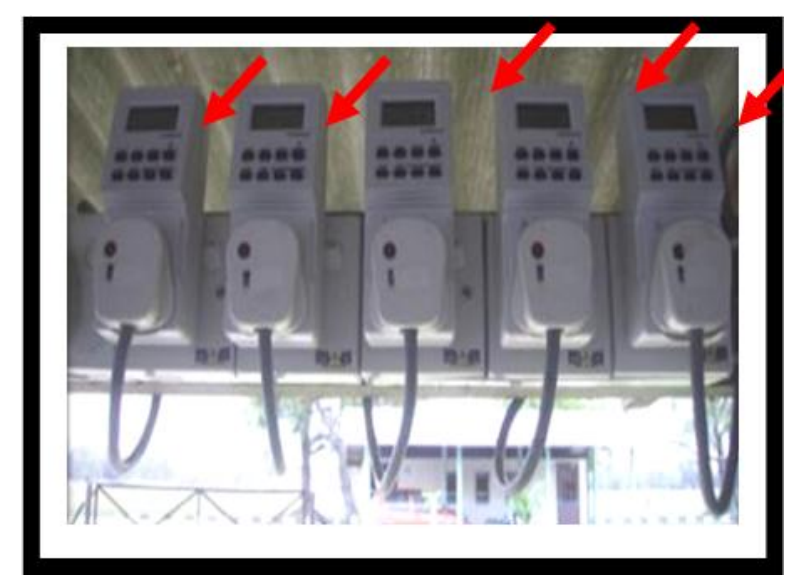

Figure 1. Microcontrollers (as indicated) device used in Micro irrigation System

\subsection{Open-Loop Control System}

An open-loop control system is controlled directly, and only, by an input signal. The basic units of this type consist only of an amplifier and a motor [14]. The amplifier receives a low-level input signal and amplifies it enough to drive the motor to perform the desired job. The open-loop control system is shown in basic block diagram form in Figure 4. With this system, the input is a signal that is fed to the amplifier. The output of the amplifier is proportional to the amplitude of the input signal. The phase (ac system) and polarity (dc system) of the input signal determines the direction that the motor shaft will turn. After amplification, the input signal is fed to the motor, which moves the output shaft (load) in the direction that corresponds with the input signal. The motor will not stop driving the output shaft until the input signal is reduced to zero or removed. This system usually requires an operator who controls speed and direction of movement of the output by varying the input. The operator could be controlling the input by either a mechanical or an electrical linkage.

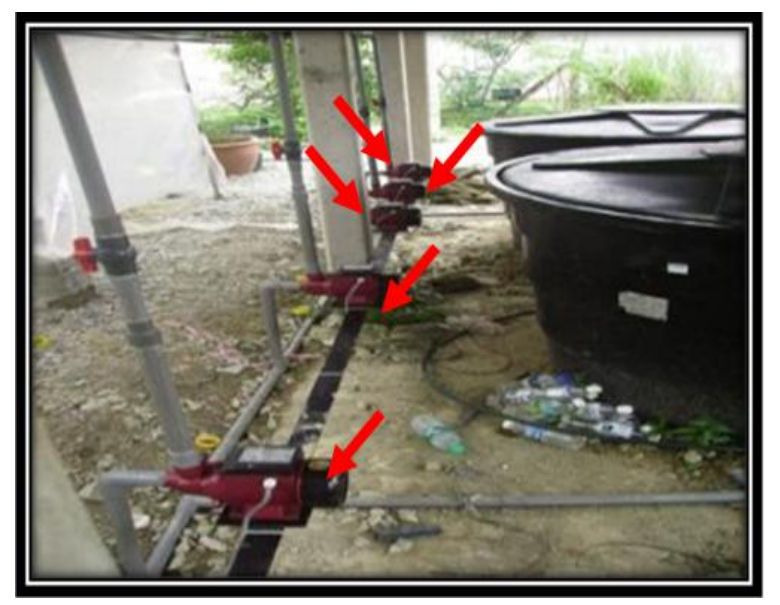

Figure 2. Water pumps (as indicated) that connected from microcontroller

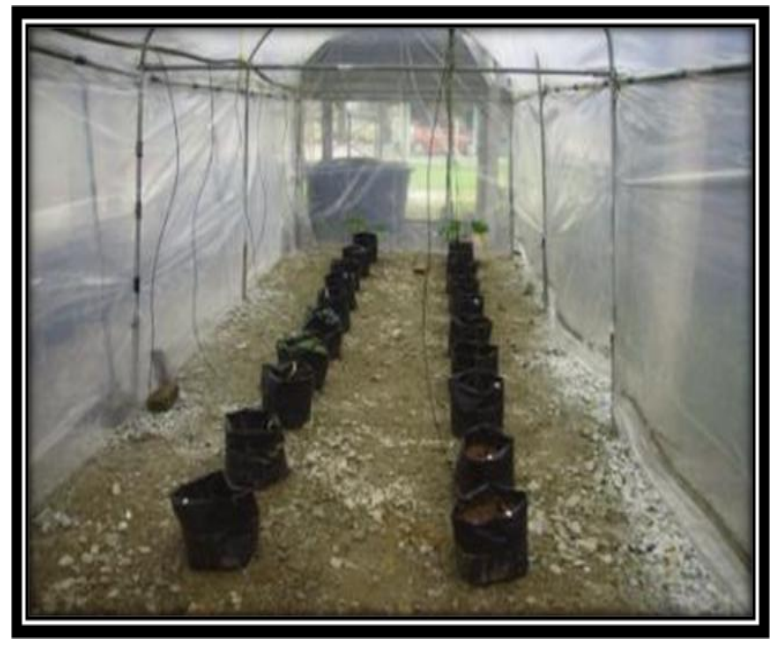

Figure 3. Water delivery system of primary and secondary

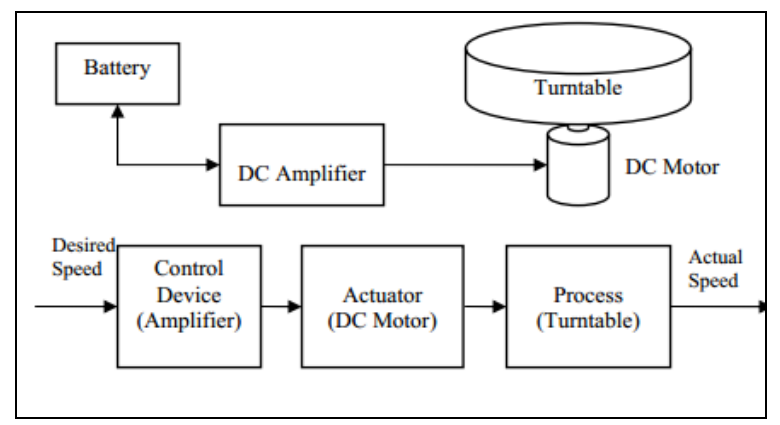

Figure 4. Open-loop control system basic block diagram 


\section{Result and Discussion}

An irrigation controller is a device to operate automatic irrigation systems such as lawn sprinklers and drip irrigation systems. Most controllers have a means of setting the frequency of irrigation, the start time, and the duration of watering. Some controllers have additional features such as multiple programs to allow different watering frequencies for different types of plants, rain delay settings, input terminals for sensors such as rain and freeze sensors, soil moisture sensors, weather data, remote operation, etc. Table 1 and Table 2 show the result of water quantity measure on various nozzle point on tested drip irrigation system. As compared between S1 and T1 indicated the volume is remain same and when the irrigation is applied on 2 times as indicated T2, the volume also remain same. This can conclude that drip irrigation is most practical and effective among different irrigation system for farm mechanization [4]. The system also can integrate and enhance with computer and controller device application [7]. There are two basic types of controllers, electric and hydraulic. Two general types of controllers are used to control irrigation systems: Open control loop systems, and closed control loop systems. The difference between these is that closed control loops have feedback from sensors, make decisions and apply decisions to the irrigation system. On the other hand, open control loop systems apply a preset action, as is done with irrigation timers. As for the controller observed at Gong Badak's farm, open control loop system is used.

Most new systems employ electromechanical or electronic controllers. In this scenario, the controller is connected to an electrical circuit that operates a solenoid attached to each valve (solenoid valve). When the solenoid is actuated, the water above the diaphragm is relieved and the valve opens [14]. There are broadly two categories of irrigation controllers: domestic ones for gardening applications, and professional controllers for more demanding agricultural applications. While most domestic (gardening) controllers can only open/close zones based on a time duration, without any feedback from the irrigation process, professional irrigation controllers can irrigate based on volume (quantities defined in cubic meters / Gallons), receive feedback from the process, and react to actual events happening during the process $[15,16]$.

Table.1. Time interval for each reading is 5 minutes

\begin{tabular}{|c|c|c|c|}
\hline Time & $00: 20-00: 25$ & $00: 30-00: 35$ & $00: 40-00: 45$ \\
\hline $\begin{array}{c}\text { Volume of water } \\
\text { collected (ml) }\end{array}$ & 665 & 690 & 675 \\
\hline $\begin{array}{c}\text { Average volume } \\
\text { of water collected } \\
(\mathrm{ml}), \mathrm{S} 1\end{array}$ & \multicolumn{3}{|c|}{676.67} \\
\hline
\end{tabular}

Table.2. Water volume measurements on nozzle replication

\begin{tabular}{|c|c|c|}
\hline Time & Duration & Volume \\
\hline $\mathrm{T} 1$ & $5 \mathrm{~min}$ & $660 \mathrm{ml}$ \\
\hline $\mathrm{T} 2$ & $10 \mathrm{~min}$ & $1260 \mathrm{ml}$ \\
\hline
\end{tabular}

Irrigation timers are simple controllers consisting of clock units capable of activating one or more subunits of the irrigation system at specific time. Functions of irrigation timer are:

i. Clock/timer: provide the basic time measurements by which schedules are executed.

ii. Calendar selection/week: this function allows definition of which days the system is to operate.

iii. Station time setting/ hour and minutes : this function allows definition of start time and duration for each session and station.

An advantage of using open-loop system such as it is simple, economical, easier to construct and stable. Disadvantage of using open-loop system it has no compensation or correction for disturbances or noises, gain cannot be easily controlled because no feedback and it is increasing in error.

\section{Conclusion}

Efficient management in agriculture irrigation is very important for the good return of the crop production. Conventional ways or instrumentation based on discrete and wired solutions presents many difficulties on measuring and control systems especially over the large geographical areas. Therefore, an automation technology and its apparatus such as drip irrigation, sensors and remote control is provided for the optimal usage of water resources in agricultural areas. Agriculture controller is a device to operate automatic irrigation systems, which can manage the flow of water through the irrigation system. Most controllers have a means of setting the frequency of irrigation, the start time, and the duration of watering.

Irrigation controllers have been available for many years in the form of mechanical and electromechanical irrigation timers. These devices have evolved into complex computer-based systems that allow accurate control of water, energy and chemicals while responding to environmental changes and development stages of the crop. This paper reviews basic concepts related to control systems for irrigation management purposes.

When using an open control loop system, a decision is made by the operator or the amount of water and the time at which this water should be applied. The operator then goes on to set an irrigation controller according the desired schedule. These devices require external intervention they are referred to in control terms as open loop systems.

Open loop control systems use irrigation duration or applied volume for control purposes. Notice that in this type of controller the basic control parameters are how often and how long is irrigation water is to be applied. Open loop controllers are also constructed in such a way that a clock is used to initiate irrigation and the application of a given volume to stop irrigation. In this type of controller the parameters set by the system operator are how often and the volume of water to be applied.

Open loop control systems have the advantages that they are low cost, readily available, and many variations of the devices are manufactured with different degrees of flexibility related to the number of stations and schedule specification. However, they do not respond automatically to changing conditions in the environment and require 
frequent resetting to achieve high levels of irrigation efficiency.

\section{Acknowledgement}

Greatest thank to the Al Mighty ALLAH who provided health and strength. The authors would like to thank all staff from Farm Unit, Universiti Sultan Zainal Abidin, Terengganu, Malaysia and students of Bachelor Agriculture and Biotechnology, UniSZA, Semester 7 $2012 / 213$. Also to those who are directly and indirectly gave their support and help for the success of this project.

\section{References}

[1] Boutheina D., Abdelhamid B., "Water saving and eggplant response to subsurface drip irrigation", Agricultural Segment, 1(2) AGS/1525, 2010.

[2] Fakhrodin G. S., Farid E., Mehdi R., Iman P., "Comparison of Tape Drip Irrigation and Furrow Irrigation Systems on Base of Water Use Efficiency and Yield of Potato in West of Iran", International Journal of Biology, ISSN 1916-968X Canadian Center of Science and Education, 2012.

[3] Mahir Dursun and Semih Ozden, "A wireless application of drip irrigation automation supported by soil moisture sensors", Scientific Research and Essays, 6(7), pp. 1573-1582, 2011.

[4] Mohd. Hudzari Haji Razali, Wan Ishak Wan Ismail and Noordin Asimi Mohd Noor, Computer and Electronic in Agriculture: Farm Mechanization Essentials, Lambert Academic Publishing, Saarbrucken, Germany, pp. 80, 2012.

[5] Mohd. Hudzari Razali, Wan Ishak Wan Ismail, Mohammad Noorman Masrek, "Parameter acceptance for software development of oil palm fruit ripeness prediction", Journal of Software Engineering, 4(3), pp. 244 -256, 2010.
[6] Mohd. Hudzari Razali, Wan Ishak Wan Ismail, Md. Nasir Sulaiman, Napsiah Ismail and Rashid Sharif, "Computer Simulation Technique for Two Degree of Freedom Agriculture Robot Arm", International Journal of Computational Intelligence Techniques, 1(2), pp. 15-17, 2010.

[7] Mohd Hudzari Haji Razali, Mat Atar and Siti Norjihah, "Human computer interaction and application in agriculture for education", International Journal of Information Technology \& Computer Science, 2(3). pp 7-11, 2012.

[8] Wan Ishak Wan Ismail, Mohd. Hudzari Razali and Muhammad Ridzuan M.N, "Development of Variable Rate Sprayer for Oil Palm Plantation". Bulletin of the Polish Academy of Sciences Technical Science. 59(3), pp. 299-302, 2011.

[9] Mohd Hudzari Razali, Aimrun W and Syahril A.H, "Precision Farming for farm Mechanization Education" Technical Journal of Engineering and Applied Sciences, 2(3).pp 79-83, 2012.

[10] Mohd Hudzari Razali, "Sprayer Technology for Farm Mechanization Course", Technical Journal of Engineering and Applied Sciences, 2(5).pp 107-112, 2012.

[11] Mohd Hudzari Haji Razali, "Computer Application In Agriculture And Mechanization Education", International Journal of Wireless Information Networks \& Business Information Network. 1(2), pp. 15-17, 2012.

[12] Mohammad V., Sprinkle and Trickle Irrigation System Design Using Tapered Pipes for Pressure Loss Adjusting, Journal of Agricultural Science; 4(12), 2012.

[13] Talat F. A., Hashim N. H., A. Razzaq G. M., (2011) Performance Assessment of Subsurface Drip Irrigation System Using Pipes of Varying Flexibility, Vegetable Crops Department, University Research Journal Of Engineering \& Technology, 30(3), July, 2011

[14] Altaf A., Keith L. B., Jirka S. U.,(2012) Minimizing nitrogen leaching from furrow irrigation through novel fertilizer placement and soil surface management strategies, Agricultural Water Management, 115 242-251, 2012 Elsevier B.V.

[15] Vera J., Abrisqueta I., Abrisqueta J.M, and Ruiz-Sánchez M. C. Effect of deficit irrigation on early- maturing peach tree performance, Irrigation Science Springer Verlag, 2012.

[16] Al-Yahyai, R. Managing irrigation of fruit trees using plant water status. Agricultural Sciences, 3, 35-43, 2012. 